\title{
Medicina tradicional e Candomblé: relato de experiência
}

\author{
Janimere Silva Soares \\ Docente. Instituto Federal de Roraima - IFRR \\ (janimere@ifrr.edu.br) \\ Cícero de Almeida Filho Cardozo \\ Docente. Instituto Federal de Roraima - IFRR \\ (cicero.gestao@ifrr.edu.br)
}

\begin{abstract}
Resumo: Este relato apresenta momentos vividos em sala de aula, na participação no II Fórum InterReligioso de Roraima e na visita a um terreiro de candomblé. O candomblé é harmonia, comunhão, tradição e culto aos orixás. Seus saberes e práticas de cura ocupam espaços na vida da população, sobretudo através do uso significativo das ervas. A saúde, nesse culto afro-brasileiro, tendo como base a mãe natureza, utiliza ervas medicinais em seus processos de cura. Os itinerários terapêuticos são os caminhos percorridos em busca do cuidado e da cura, em função do acesso ao serviço de saúde, recursos sociais, culturais, crenças, entre outros, dos quais muitas pessoas buscam seus próprios curandeiros, desejando uma visão holística envolvendo corpo, mente e espírito. Este relato tem como propósito contribuir para um maior entendimento da população sobre a prática do candomblé e sua relação com a medicina tradicional. A fundamentação teórica para a construção deste relato teve como base algumas referências para dar suporte às reflexões. Conclui-se que a medicina tradicional, através de seus membros, utiliza seus conhecimentos sobre as propriedades medicamentosas das plantas medicinais, atuando através de suas experiências e práticas no tratamento, diagnóstico e prevenção de doenças.
\end{abstract}

Palavras-chave: Erva medicinal; Práticas de Cura; Religião Afro.

\section{Traditional medicine and Candomblé: experience report}

Abstract: This report presents moments lived in the classroom, in the II Interfaith Forum of Roraima participation and in the visit to a candomblé terreiro. Candomblé is harmony, fellowship, tradition and worship of deities. Their knowledge and healing practices occupy spaces in people lives, especially through significant use of herbs. The health, in this african-Brazilian cult, based on mother nature, uses medicinal herbs in their healing processes. Therapeutic Itineraries are the paths taken in pursuit of care and cure, due to access to health services, social resources, cultural beliefs among others of which many people seek their own healers wishing a holistic vision involving body, mind and spirit. This experience report aims to contribute to a better understanding of the population about the practice of Candomble and its relationship to traditional medicine. The theoretical basis for the construction of this report was based on some references to support reflections. It was concluded that traditional medicine, through its members, using their knowledge of the medicinal properties of medicinal plants acting through their experiences and practices in the treatment, diagnosis and prevention of diseases.

Keywords: medicinal herb; healing practices; African religion.

\section{INTRODUÇÃO}

O interesse maior neste estudo foi descrever a prática do candomblé e como é construído o conceito e o sentido do processo saúde-doença-cura por meio dos 
seus vários itinerários terapêuticos. Muitas vezes a precariedade na oferta da saúde pública no país, suas limitações e a dificuldade de acesso para algumas populações os levam de certa forma a buscar práticas mais populares. O candomblé, seus saberes e práticas de cura ainda ocupam espaços fragmentados na vida da população, sobretudo através do uso significativo das ervas com fins terapêuticos. Com este estudo busca-se contribuir para o entendimento desse segmento da população sobre a religião afro-brasileira, através da resistência cultural dos ancestrais, e sua relação com a medicina tradicional.

Confesso que ao ser aprovada no mestrado em Ciências da Saúde pela Universidade Federal de Roraima, e ao inscrever-me em uma disciplina obrigatória chamada "Saúde e Diversidade Sociocultural da Amazônia", o componente curricular oportunizou o estudo de uma forma ampla e detalhada das seguintes temáticas: antropologia da saúde; conhecimentos, saberes e medicina indígena e não indígena; população afro-brasileira. Um tema me chamou a atenção de forma particular foi o candomblé.

No primeiro momento, a discussão desse assunto em sala de aula suscitou estranheza entre os alunos da turma e também me incluo nesse processo, principalmente quando o professor informou que nos levaria a um terreiro. $O$ desconhecimento da cultura africana através da religião candomblé ainda é uma das causas do preconceito para com aqueles que se dizem adeptos desse culto.

Durante as aulas no mestrado, houve dois momentos que contribuíram para acrescer meus conhecimentos sobre o candomblé. O primeiro foi a minha participação como ouvinte do II Fórum Inter-Religioso de Roraima; o segundo foi a visita do Pai de Santo Júlio na sala de aula, a convite do nosso professor da disciplina "Saúde e Diversidade Sociocultural da Amazônia". O convidado expôs a temática de forma tão clara que, ao final, já me sentia munida de conhecimento para sustentar um diálogo sem muita timidez, do qual descreverei alguns aprendizados adquiridos nestas ocasiões.

A fundamentação teórica para construção deste relato teve como base os textos apresentados no plano de aula da disciplina supracitada e discutidos em grupo a cada semana. Outras referências fizeram-se necessárias para dar suporte às reflexões ao embasamento para construção deste trabalho. É nesse contexto que se situa meu relato de experiência. 


\subsection{O Candomblé e o processo de cura pela ervas medicinais}

$\mathrm{Na}$ tentativa de desnudar-me do pré-conceito a respeito da religião afrodescendente, resolvi aprofundar meus conhecimentos sobre o assunto. Muitas vezes a falta de informação nos leva a fazer um pré-julgamento a respeito do que julgamos ser certo ou errado. Essa questão fica visível quando temos que opinar sobre uma religião que não seja uma das mais seguidas pela sociedade. Nesse momento, sentimos dificuldade, pois não estamos acostumados a formular argumentos que justifiquem nosso posicionamento frente ao tema. Por essa razão, me senti motivada a registrar os momentos vividos durante a visita a um terreiro de candomblé em Boa Vista (RR).

No decorrer das atividades de estudo propostas em sala de aula, recebemos o convite de um dos colegas para participarmos de uma festa de obrigação em um terreiro de candomblé, "Terreiro do Oxóssi", casa de raiz Angola. Na prática da religião se entende por obrigação as festividades de honra aos Orixás, por meio dos adeptos da crença. De acordo com Mota (2011, p. 330), "há os rituais de obrigação, nos quais o fiel aprende a cuidar da entidade, e os rituais de confirmação, nos quais o fiel dará continuidade às suas obrigações rituais e mantendo a cura”.

O dia da visita foi marcado e o sentimento de medo pelo desconhecido se agregava com a vontade de conhecer de perto esse espaço sagrado frequentado por descendentes africanos que buscam nesta religião fazer com que o homem conheça a si mesmo através dos orixás, buscando sempre uma harmonia e equilíbrio entre o homem, a natureza e Deus.

Chegando ao terreiro, as expectativas e os anseios que pairavam no ar eram o do poder mágico e misterioso. Em meu olhar de observadora e de aprendiz ávida pelo saber, procurava perceber as características de cada espaço. Muitas vezes não sabendo o que fazer, o que perguntar (até mesmo se poderia perguntar algo), se seria autorizado fotografar o ambiente. Notadamente todos os alunos presentes expressavam uma sensação de estar olhando um mundo a ser descoberto. De acordo com Oliveira et al. (1988, p. 19), "[...] a pesquisa da realidade, capacitação de quadros e aquisição de conhecimentos são dimensões inseparáveis e interligadas. E [...] o estudo da realidade vivida pelo grupo e de sua percepção desta mesma realidade constituem o ponto de partida e a matéria-prima para o processo educativo". Conhecer o terreiro naquele momento de festa, toda simbologia e seus 
rituais foi um momento ímpar. Especialmente porque tivemos permissão para fotografar e filmar o ritual. Certamente ali iniciava meu processo de construção do relato de experiência, como um dos critérios de avaliação da disciplina do mestrado.

Os filhos e filhas de santos que participavam do ritual estavam vestidos com roupas caracterizando o seu orixá ${ }^{1}$. Toda simbologia do candomblé pode ser evidenciada nas roupas, cores, na utilização de condregums (braceletes que usam nos braços), nos cultos e na festa, que é considerada a celebração religiosa máxima da liturgia do sagrado. Araújo (2013, p. 46) relata que "a tradição religiosa afrobrasileira é parte do legado deixado por homens e mulheres africanos e afrobrasileiros, que contribuíram de forma significativa para a construção do país em que vivemos", "O terreiro é um espaço de afirmação do povo negro, espaço esse marcado pela resistência contínua de um povo que soube manter o culto aos ancestrais sendo a maior forma de resistência dos antepassados africanos." Segundo Araújo (2013, p. 23).

Esse mesmo espaço é considerado local de combinação entre equilíbrio, paz e saúde. A saúde tendo como base a mãe natureza, a qual oferta as ervas medicinais que utilizadas nos processos de cura. São espaços, também conhecidos como barracão, destinados ao culto dos orixás, ao resguardo do iniciado, das obrigações e toda simbologia da religião afro-brasileira praticada pelos candomblecistas.

Fui recebida pela mãe de santo, a qual pediu para que eu ficasse à vontade e se dispunha a colaborar no que fosse preciso. Aproveitei este momento para convidá-la a sentar-se conosco (alunos do mestrado), a fim de nos esclarecer algumas dúvidas. No entendimento de Oliveira et al. (1988, p. 30), "muitas vezes, não é unicamente aquilo que é dito explicitamente, que é significativo. A maneira de dizer, as inflexões, as hesitações, as pausas e os silêncios dizem muita coisa".

Para nossa surpresa ela nos apresentou ao Pai de Santo daquela casa. Neste momento a soma o sentimento de acolhimento e o processo de anotação de todas as informações teve início. O Pai de Santo nos revelou que uma de suas filhas biológicas é evangélica de uma igreja cristã e que em nenhum momento há desrespeito entre eles. Reina uma convivência harmoniosa entre o pai e a filha.

\footnotetext{
1 Orixás são deuses africanos que correspondem a pontos de força da Natureza e os seus arquétipos estão relacionados às manifestações dessas forças.
} 
Sobre esse assunto, Santos (2009, p. 40) nos oferece uma descrição sobre a prática do cristianismo em comparação com a prática do candomblé:

\begin{abstract}
A proposta cristã de salvação contrasta indelevelmente com a experiência simbólica do universo dos candomblés. Enquanto a igreja ofereceria uma salvação depois da morte, os candomblés proporcionariam uma dinâmica de vida que entrelaça os níveis de existência, ou seja, humanos, ancestrais e divindades compartilhariam níveis diferentes de uma mesma experiência. Esses níveis estão em constante comunicação, motivo pelo qual não é necessário esperar a morte para alcançar o bem-estar.
\end{abstract}

Desta forma, mesmo com contrastes tão fortes entre as duas práticas religiosas, as pessoas com diferentes opiniões podem conviver, diante de um pacto de respeito com o mediador das relações.

Ao iniciar a festa comecei a registrar os principais momentos do terreiro, das danças, dos rituais. Alguns momentos foram marcantes, como: a cerimônia de abertura; o momento em que uma frequentadora do terreiro incorporou um orixá; o momento de transe e incorporação do Erê (orixá) e o momento mais esperado da festa, que foi a saída da laô (entidade). A tensão e a expectativa eram visíveis entre os presentes naquela cerimônia.

Neste espaço religioso, considerado um local de proteção e cura do espírito, existe a expressão "corpo fechado", que se traduz na proteção e no impedimento de um mal do mundo externo, de modo a não atingir o espírito. O corpo estar estreitamente ligado à noção de pureza (SILVA, 2003).

Ao término do festejo (durante a nossa visita), todas as filhas da casa ocuparam seus postos e começaram a distribuir a comida, ritual de um banquete muito farto composto por cabrito assado ou cozido. Havia também um bolo imenso, que foi servido a todos. A festa no candomblé não se encerra após a saída da laô ou quando os tambores param de tocar, mas depois da comida servida como forma de agradecer a bênção e a graça recebida. Momento esse refletido por meio da distribuição dos alimentos a todos os presentes (GÓIS, 2013).

Além dos momentos de festa e dos rituais, no cotidiano do terreiro o clima é sempre harmonioso e familiar e que também exercem suas atividades costumeiras. Pode-se observar esse fato por meio da ação das mulheres que sempre estiveram atarefadas na cozinha na preparação das festas e obrigações com os orixás. 
Por meio da participação na cerimônia religiosa, pude perceber como esta prática religiosa está aliada à medicina tradicional, permeando até os dias de hoje na vida da população. Isto foi evidenciado na fala do Pai de Santo, quando relatou sobre a importância da utilização de plantas medicinais no processo de cura e que lá neste terreiro eles possuem várias dessas plantas, dentre elas a hortelã, a pitanga, a alfazema e outras. Nesse sentido, Baptista (2007, p. 96) nos alerta que a utilização da medicina tradicional, considerada primitiva na atualidade é uma dificuldade devido ao súbito avanço da ciência.

Se avaliarmos pelo âmbito da patologia, o corpo é a sede da doença, não havendo relação com as questões espirituais e nem cosmológica. Os estudiosos da saúde dividem o corpo por áreas a serem estudadas, compreendidas no objetivo da identificação da doença no processo de cura, do qual a doença é constituída por sinais e sintomas que leva a um diagnóstico necessário a escolha do uso de medicamentos, tratamento apropriado e até mesmo cirurgias.

Ao entendermos a medicina moderna, muitas vezes com uma abordagem bastante reducionista, ou seja, com foco no corpo do paciente, não cabe aqui as questões que envolvem a medicina tradicional através do uso das ervas medicinais e outros métodos ainda não reconhecidos cientificamente pela medicina oficial. Helman (2007, p. 117) destaca que "a patologia é algo que um órgão tem; a perturbação é algo que uma pessoa tem. A perturbação é uma resposta subjetiva de um indivíduo".

Não obstante, diante de situações de infortúnio, muitas pessoas ainda buscam alternativas com vistas ao processo de cura, cabendo enfatizar aqui que a fé é tida como um dos fatores principais. As questões que envolvem a doença vão além de um processo puramente fisiológico. Dependendo do contexto cultural em que essas pessoas se encontram o significado da crença em um ser superior ainda não explicável através de uma forma técnica e científica, representa e influencia diretamente o poder de cura.

Sobre essa questão Helman (2007, p. 117) aduz:

Em muitas sociedades, todas as formas de infortúnio são atribuídas à mesma variedade de causas; uma febre alta, uma quebra de safra, o roubo de uma propriedade ou o desabamento de um telhado podem ser todos atribuídos à feitiçaria ou a punição divina por alguma transgressão moral. No último caso eles podem provocar emoções 
semelhantes de vergonha ou culpa e exigir tipos parecidos de tratamento, como reza ou penitência.

$\mathrm{Na}$ tradição das religiões afro-brasileiras, a enfermidade e a morte podem estar relacionadas muitas vezes a feitiços e ações de espíritos, desobediências ou punições. A figura do curandeiro é de extrema importância, por ser o detentor de um poder sobrenatural capaz de realizar a arte da cura.

A medicina tradicional, através de seus membros, utiliza seus conhecimentos sobre as propriedades medicamentosas das plantas medicinais atuando através de suas experiências e práticas no tratamento, diagnóstico e prevenção de doenças (BAPTISTA, 2012). Práticas essas que envolvem a acupuntura, homeopatia, curandeiros e parteiras.

A Organização Mundial de Saúde (OMS) conceitua Medicina Tradicional como:

A soma total do conhecimento, habilidades e práticas com base nas teorias, crenças e experiências indígena para diferentes culturas, quer explicáveis ou não, usados na manutenção da saúde, bem como para a prevenção, diagnóstico, melhoria ou o tratamento de doenças físicas e mentais.

As ervas medicinais sempre fizeram parte da vida de seus agentes como bezendeiros, curandeiros, pajés. Agentes detentores de um saber herdado de suas ancestralidades (ARAÚJO, 2013, p. 24). Ainda no entendimento de Araújo, "costuma-se dizer enquanto estratégia de promoção da saúde nos terreiros, que os orixás protegem aqueles que se cuidam, que buscam informações e que as multiplicam".

A medicina tradicional africana, através de seus conhecimentos científicos e subjetivos, permanece realizando a arte da cura. Conhecimento científico adquirido de forma empírica através do uso de plantas medicinais e o conhecimento subjetivo adquirido através de um ser superior divino. Para essa combinação de conhecimento faz-se necessário também o estado de espírito do paciente, influenciando diretamente no processo de cura.

A diversidade de saberes adquirida por esses agentes é demostrada através de suas práticas de cura utilizadas na medicina tradicional através das plantas medicinais: "O estado de espírito dos pacientes também tem grande influência, fazendo com que a cura seja mais rápida" (BAPTISTA, 2007, p. 62). 
São através dos conhecimentos tradicionais dos curandeiros, rezadores, benzedeiros, que os mesmos realizam a arte da cura e a arte do cuidar, independentemente dos terreiros de candomblé. Tais práticas são muitas vezes procuradas por pessoas que acreditam que o processo de cura não é somente encontrado na medicina oficial praticada pelo médico. Os chamados doutores ou doutoras da raiz são pessoas que conhecem profundamente as meizinhas, (remédios), cada qual com sua finalidade atuando em cada problema ou doença. Os curandeiros, através dos remédios populares com produtos feitos com ervas regionais, detêm o saber da cura. O raizeiro é o que prepara os remédios e sabe o efeito de cada um. O benzedeiro também é alguém próprio da comunidade que tem o dom de curar com ervas e orações. Toda essa tradição está alicerçada em uma cosmovisão mítica religiosa (SILVA, 2003).

A prática da medicina tradicional também é muito comum nos sistemas xamãnicos amazônicos, utilizando bebidas a base de ervas, consideradas como "plantas psicotrópicas ou plantas de poder e de conhecimento" (yagé ou Ayahuasca) ingeridas pelo xamã, considerado o líder espiritual, durante sua performance de cura. Esses rituais presentes no sistema de saúde indígena apresentam a forte relação entre a natureza e processo de cura do qual o líder espiritual possui como uma capacidade sobrenatural (LANGDON, 2013, p. 81).

É necessária uma relação harmoniosa entre a natureza, os seres humanos e o sagrado, pois quando não há esse equilíbrio, o homem é acometido por doenças através de forças sobrenaturais. Portanto, "saúde é a harmonia do universo e de cada um de seus componentes: o vegetal, o mineral e o animal, o material e o espiritual" (BAPTISTA, 2007, p. 60).

Diante da construção da visão de mundo a respeito dos itinerários terapêuticos ${ }^{2}$ e seus mecanismos de cura, não podemos deixar de destacar a relação entre o terreiro, a saúde e a cura. No Brasil existe uma enorme ligação entre saúde e religião. A maioria das pessoas considera a doença causada tanto por fatores biológicos como espiritual, ou até mesmo por fator mágico, como o feitiço.

\footnotetext{
${ }^{2}$ Itinerários terapêuticos são as diferentes práticas em saúde e os caminhos percorridos em busca de cuidado, nos quais se desenham múltiplas trajetórias (assistenciais ou não, incluindo diferentes sistemas de cuidado), em função das necessidades de saúde, das disponibilidades de recursos sociais existentes sob a forma de redes sociais formais e informais e da resolutividade obtida (ARAÚJO, 2013, p. 35).
} 
Por essa razão as pessoas diariamente procuram hospitais, centro espíritas, terreiros, benzedeiras. Cabe aqui enfatizar no âmbito da medicina oficial e sua importância como fator científico, mas cabe relacionar a religiosidade como algo subjetivo e cultural significando muitas vezes o poder da fé para o processo da cura.

Os itinerários terapêuticos realizados pelas pessoas acometidas por alguma enfermidade podem envolver diversos campos da medicina tradicional e da medicina oficial, diferenciado muitas vezes pela sua cultura e fé implicando instâncias, como: autocuidado, rituais religiosos e dispositivos biomédicos como atenção primária e hospitalar.

O setor biomédico ainda caracteriza a medicina tradicional e as práticas terapêuticas holísticas como baseadas na ausência de uma validação científica. Apesar do vasto conhecimento ancestral da biodiversidade, as populações que detêm esses saberes são caracterizadas ainda por sua invisibilidade social (BAPTISTA, 2007, p. 67). Muitas vezes formadas por pobres, negros, índios e pessoas sem destaque na sociedade e que carregam um estigma em suas profissões.

Segundo Sen (2000, p. 275), hoje no mundo mais globalizado os costumes culturais nativos estão sendo destruídos aos poucos, através de um processo onde a competitividade está cada vez mais alavancada pela evolução tecnológica.

Recentemente a OMS publicou uma versão intitulada estratégia da medicina tradicional 2014-2023, com o intuito de ajudar as autoridades sanitárias na busca de uma melhoria da saúde da população através da utilização segura e eficaz da medicina tradicional mediante a regularização dos produtos, práticas e profissionais (WORLD HEALTH ORGANIZATION, 2014). Contribuindo para que muitos países reconheçam a necessidade de desenvolver um cuidado integral envolvendo tanto os governos quanto os profissionais de saúde.

O candomblé é uma religião de matriz africana, evidenciada por muita disciplina entre seus seguidores e que aos poucos foi se aglutinando no Brasil, onde por meio de seus rituais, mitos e toda simbologia viajou através da diáspora africana, sendo reestruturada em terras brasileiras.

Caputo e col. (2007, p. 107) relatam que: 
gerações que não só mantiveram muito das outras práticas culturais desses povos desterritorializados, como também mantiveram as pessoas unidas, compartilhando não somente crenças e identidades.

No período colonial, o escravo africano, por ser mercadoria isenta de impostos de entrada no Brasil, a sua fixação provocou uma mudança radical na organização do trabalho, principalmente na Amazônia (FARAGE, 1991).

Durante este período, os escravos africanos praticavam o candomblé de uma forma disfarçada, pois para os olhos de seus senhores, esses negros estavam realizando danças nativas de seu país. Mas, por ser caracterizado pelos cultos aos Orixás dos distintos povos africanos traficados e escravizados no país, era exatamente nesse momento que cultuavam seus deuses. Essa conduta conduzia ao encontro do que era imposto pela doutrina católica na época.

Retomando a um processo histórico da Constituição Federal de 1891, a qual assegura a liberdade religiosa pelos povos brasileiros, separando a igreja e o estado, alguns locais ditos como letrados da sociedade impediam que o candomblé fosse considerado uma religião e o relacionavam como crimes e feitiçarias (SANTOS, 2009). Este fato foi vivenciado por aqueles que seguiam a religião afrobrasileira e que lutavam pelo direito conquistado por meio da constituição.

Depois de promulgada a Constituição Federal de 1988, em seu Artigo 5ํㅡㄴ Inciso VI, foi assegurado o exercício dos direitos humanos sociais e individuais, direitos à igualdade, a liberdade entre outros como podemos citar: "é inviolável a liberdade de consciência e de crença, sendo assegurado o livre exercício dos cultos religiosos e garantida, na forma da lei, proteção aos locais de culto e a suas liturgias".

Recentemente um assunto que apresentou repercussão na mídia nacional foi o fato de um Juiz Federal do Estado do Rio de Janeiro afirmar que o candomblé não se constitui em religião por não conter os traços necessários de uma religião como uma estrutura hierárquica, um texto base (Corão, Bíblia) e a ausência de um Deus a ser venerado (FOLHA DE SÃO PAULO, 16 maio 2014). Por ignorar os princípios da oralidade, da ancestralidade e das tradições religiosas afro-brasileiras, este juiz viola a constituição e as próprias leis que asseguram o livre exercício dos cultos religiosos.

A oralidade é um processo que possibilita a composição de uma cultura através da expressão de forma oral resgatando toda ancestralidade afro-brasileira. 
Por não ter um registro escrito, mas por haver uma valorosa história, essa transmissão vem até os dias atuais como uma forma de troca de conhecimento através do processo natural de suas convivências entre os povos, construídos por saberes resgatado da ancestralidade da matriz africana. O princípio da oralidade representa uma raiz do conhecimento oportunizando a comunidade conhecer essa cultura (ARAÚJO, 2013).

Foi durante o período da escravidão que os negros africanos instalados em vários estados brasileiros tentaram fixar sua tradição religiosa. Sem a força da religião talvez não houvesse como suportar a vida sub-humana à qual eram submetidos. A contribuição das divindades foi essencial nesse momento. Foi por meio da visita ao terreiro que pude perceber que nos tempos modernos a luta pela permanência da cultura ainda persiste, "A diferença entre cultura humana e as condições de vida entre elas devem-se as circunstâncias que as cercam, plenas de necessidades e obstáculo a serem ultrapassados e de tradições herdadas do passado." no entendimento de Costa (2005, p.15).

São problemas enfrentados por aqueles que lutam na tentativa de manter sua cultura viva e representada nos dias atuais. O candomblé é harmonia, comunhão, tradição e culto aos orixás. É sinônimo de batuque, relacionando-se com as práticas de cura e adivinhação. É uma religião que busca comunhão entre os seres humanos e a natureza. É a crença aos orixás representados por um espírito divino que vem do alto, ou seja, são ancestrais divinizados africanos correspondendo a um ponto de força da natureza. Na África há menção de cerca de 200 deuses cultuados, dentre esses 16 orixás são cultuados no Brasil quais sejam: Ogum, Xangô, Oxum, lemanjá entre outros. O grande número de deuses cultuados na África naquela época, era pelo fato da mesma ser dividida em aldeias e cada aldeia tinha o seu orixá (ARAÚJO, 2013).

Também como característica, o candomblé apresenta um caráter humanista desprovido do pensamento preconceituoso de exclusão da cor, do sexo e da origem social. Segundo Silva (2003, p. 79), "essas religiões são vistas como locais em que há um respeito maior para a diversidade e as questões morais são menos fortes sobre o que é pecado e profano, pois não tem uma separação tão rígida".

Esta religião também é caracterizada fortemente pelo emponderamento feminino, ou seja, o poder da mulher com o surgimento de grandes sacerdotisas. 0 matriarcado no período colonial, especificamente após a abolição da escravatura foi 
evidenciado na manutenção do legado de seus ancestrais. Principalmente por meio da força da mulher negra africana, que se destacou nas ruas e esquinas das cidades vendendo alimentos para subsistência da família. Por meio dos cantos e danças, as mulheres mantinham sua ligação com os orixás fortalecendo as manifestações espirituais. Portanto, "foi a mulher africana e afrodescendente quem gerou, gestou e pariu a religião afro-brasileira" (D'OGUM apud SILVA, 2003, p. 100).

Apesar de o matriarcado ter presença física, nota-se a grande importância do homem nas manifestações de incorporação, ou seja, é ele quem assume a chefia espiritual. Mas tanto o homem quanto a mulher podem incorporar ou ser Pai ou Mãe de Santo. Por não existir uma linha que demarque os gêneros, os homens podem incorporar entidades femininas e vice-versa (D'OGUM apud SILVA, 2003).

Por não ser uma religião em massa, cada casa tem sua própria liturgia, da qual a autoridade máxima é o sacerdote ou a sacerdotisa. No candomblé cada terreiro necessita seguir as regras da casa. Não se estabelece proselitismo religioso e não pregam à conversão, seus adeptos aderem à religião de acordo com interesse próprio. Muitas vezes o elemento que desperta o desejo de filiação esta relacionado com o processo saúde-doença.

Os primeiros serviços de cura no candomblé ocorreram ainda no século XVII, quando devido à falta ou a deficiência da medicina oficial, os negros e não negros buscavam tal serviço. Devido a grande ligação com o universo sagrado essa prática foi sendo amplamente utilizada por meio do seu vasto potencial mítico e a associação com o uso de ervas medicinal. Assim, o significado da saúde-doença estar diretamente ligado ao universo sagrado buscando sempre o equilíbrio (MOTA e col., 2011). No candomblé há um processo de troca, uma reciprocidade entre o homem e a divindade, geralmente ligados a sacrifícios, trabalhos e doações ao orixá que irá realizar a cura. São as chamadas oferendas que os orixás pedem em troca da realização dos pedidos da saúde. Muitas vezes essas oferendas envolvem o sacrifício de animais.

A medicina concebida pelo candomblé, presente nos espaços urbanos e rurais das cidades, coloca-se como uma opção diante das necessidades da atenção à saúde, apesar da situação marginal e estigmatizadora, cuja associação remonta ao processo histórico da religião. (ARAÚJO, 2013, p. 23) 
Vale lembrar que na medicina tradicional, vista como um dos mecanismos acionados pela população, a fé é sempre tida como o significado de esperança, de algo que vai mudar para melhor.

Nos terreiros de candomblé as categorias sociais e da doença são compreendidas através de uma percepção cosmológica e religiosa, da qual o diagnóstico e tratamento dos males são realizados por meio de um aprendizado específico envolvendo a magia e os deuses nesse processo. Existe uma relação muito forte entre a pessoa que colhe e manuseia as ervas com o sagrado, 0 equilíbrio, a saúde. Nos terreiros tudo é considerado sagrado. A importância da realização dos cânticos evocativos no momento da coleta e preparações das ervas, tem um significado divino. Pode significar também a demonstração de que a força através do $a_{x e ́}^{3}$ esteja diretamente ligada à saúde e a vida, levando a um equilíbrio ou desequilíbrio do indivíduo.

Segundo Caputo e col. (2007, p. 107), "o candomblé apresenta práticas importantes como: o jogo de búzios, a rezadeira, o axexê que é o ritual fúnebre", entre outros. No cotidiano do candomblé a esteira é um artefato muito presente, pois é nela que os filhos e filhas de santo sentam-se durante os rituais e também nas obrigações dos iniciados. A presença constante de elementos minerais nos terreiros tem como objetivo de manter o bem estar físico entre eles. Nesse espaço de afetividade, a saúde é entendida como um bem e que promovê-la é de responsabilidade de todos.

Nesse sentido, o processo de iniciação no candomblé significa "nascer outra vez e nascer para uma vida completamente dedicada aos orixás" (CAPUTO e col., 2007, p. 96). Ser iniciado significa pertencer a uma nova família de Santo. Eles saem da vida material e nascem na vida espiritual. $O$ iniciante independente de sua idade biológica pode ser integrado ao grupo mesmo quando se é criança, isso quer dizer que é igualmente respeitado pelos mais velhos. Os iniciantes passam por um processo ritual, ou seja, cumprindo suas obrigações de 01, 03, 07, 14 e 21 anos onde atinge o grau de sacerdote brasileiro. "É por meio dos ritos de iniciação à religião que os elos de parentesco serão estabelecidos. Isto é, iaôs que se deitam no mesmo barco tornam-se irmãos, lideranças religiosas tornam-se pais e mães [...]" (ARAÚJO, 2013, p. 53).

\footnotetext{
${ }^{3}$ Axé significa força invisível, mágica e sagrada.
} 
A consciência de que o candomblé é uma religião de matriz africana vem sendo desmistificada aos poucos, portanto, o processo de re-africanização, como movimento de retomada das tradições africanas busca os fatores de sua matriz para sustentação dessa cultura. Segundo Santos (2009, p. 28), "algumas mídias no Brasil identificava o candomblé como a degeneração da família, da sociedade e até mesmo da raça, representando-o como o lugar de bródios e orgias, também se referindo, por meio da expressão missa negra”.

O fazer saúde não é feito unicamente nos espaços compreendidos pela medicina social. Não importando também, a técnica utilizada e seus agentes na realização da medicina tradicional. Importa a convicção de que esses conhecimentos e práticas de cura são tidos como um modo complementar face às novas diretrizes quanto às doenças e a saúde pública no país.

\section{CONSIDERAÇÕES FINAIS}

Diante dessa experiência, foi possível perceber que a medicina tradicional e os Itinerários Terapêuticos são os caminhos percorridos em busca do cuidado, em função do acesso ao serviço de saúde, recursos sociais, culturais, crenças entre outros. Muitas pessoas buscam seus próprios curandeiros, desejando uma visão holística que envolve corpo, mente e espírito. Neste caso, os modos de diagnóstico e tratamento dos pacientes por meio da medicina ocidental ainda não são suficientes por não envolver o ser de forma integral, almejada por aqueles que estão necessitando da cura. Por isso, recorrem a práticas simbólicas como os terreiros de candomblé na busca de uma relação mítica com seus orixás, a natureza e o processo de cura, alicerçada em um mecanismo que envolve a fé e a crença em primeiro plano, priorizando a primazia do sagrado.

Mesmo diante de episódios marcados por discriminação e perseguição, tal religião afro-brasileira persiste até os dias atuais como espaço fragmentado e na tentativa de legitimar e viabilizar a garantia deste espaço sagrado, utilizando também métodos fitoterápicos por adeptos ou não dessa religião, como possibilidade de escolha desta prática no processo de cura. O aprofundamento do conhecimento sobre esse assunto é fundamental no processo de desmistificação da religião candomblé e seu processo de cura através de plantas medicinais. 


\section{REFERÊNCIAS}

ARAÚJO, K. A. Concepção de Saúde-Doença-cuidado relacionada às práticas do candomblé em Boa Vista. Dissertação de mestrado. Boa Vista: PROCISA/UFRR, 2013.

BAPTISTA, E. R. Conhecimentos e práticas de cura em Comunidades Rurais Amazônicas: Recursos Terapêuticos Vegetais. Manaus: EDUA/Naea, 2012. Cap. 2 e 3. P. 57-125.

BRASIL. Constituição (1891). Constituição da Republica dos Estados Unidos do Brazil. Rio de Janeiro. Em 24 de fevereiro de 1891, 3ํ da Republica.

BRASIL. Constituição (1988). Constituição da República Federativa do Brasil. Brasília, DF: Senado Federal, 1988. 292 p.

CAPUTO, S. G.; Passos, M. CULTURA E CONHECIMENTO EM TERREIROS DE CANDOMBLÉ - lendo e conversando com Mãe Beata de lemanjá. Currículo sem Fronteiras, v. 7, n. 2, pp. 93-111, Jul/Dez 2007. Universidade do Estado do Rio de Janeiro. Rio de Janeiro, Brasil.

COSTA, M. C. C. Sociologia: introdução à ciência da sociedade. 3. ed. rev. e ampl. São Paulo: moderna, 2005.

D'OGUM, V. O matriarcado na religião afro-brasileira. In: SILVA, José Marmo (org). Religião afro-brasileira e saúde. São Luiz, 2003. Centro de cultura negra do Maranhão. p. $100-102$.

FARAGE, N. As muralhas dos Sertões: Os povos indígenas no Rio Branco e a Colonização. Rio de Janeiro: Paz e Terra; NA'POCS, 1991.FOLHA DE S. PAULO. Disponível em: <http://www1.folha.uol.com.brl>. Acesso em: 27 jun. 2014.

GÓIS, A. J. As religiões de matrizes africanas: o Candomblé, seu espaço e sistema religioso. Belo Horizonte, v. 11, n. 29, p. 321-352, jan./mar. 2013.

HELMAN, C. Cultura, Saúde e Doença. 5. ed. Porto Alegre. Artes Médicas, 2009.

LANGDON, E. J. La eficacia simbólica de los rituales: del ritual a la performance. In: Labate BC, Bouso JC, editores. Ayahuasca y salud. Barcelona: Los Libros de La Liebre de Marzo; 2013. p. 80-119.

MOTA, C. S.; Trad, L. A. B. A Gente Vive pra Cuidar da População: estratégias de cuidado e sentidos para a saúde, doença e cura em terreiros de candomblé. Saúde Soc. São Paulo, v. 20, n. 2, p. 325-337, 2011.

OLIVEIRA, R.; OLIVEIRA, M. Pesquisa social e ação educativa. In: BRADÃO, Carlos R. (Org). Pesquisa participante. 7. ed. Brasiliense, 1988.

SANTOS, E. F. O poder dos candomblés: perseguição e resistência no Recôncavo da Bahia. Salvador: EDUFBA, 2009.

SEN, A. K. Desenvolvimento como liberdade. São Paulo: Companhia das Letras, 2000. 
SILVA, J. Religiões afro-brasileiras e saúde no Maranhão. Centro de Cultura Negra no Maranhão, 2003. Cap. 3. p. 76-111.

WORLD HEALTH ORGANIZATION. WHO traditional medicine strategy: 2014-2023. 